\title{
Innovation networks in the refurbishment sector of Austria: promising approaches waiting for market success
}

\author{
Michael Ornetzeder* \\ Institute of Technology Assessment \\ Austrian Academy of Sciences \\ Strohgasse 45/5 \\ A-1030 Wien, Austria \\ Fax: ++43-1-71098 83 \\ E-mail: michael.ornetzeder@oeaw.ac.at \\ *Corresponding author
}

\section{Jürgen Suschek-Berger}

Inter-University Research Centre for Technology,

Work and Culture (IFZ)

Schlögelgasse 2

A-8010 Graz, Austria

Fax: ++43-316-8102 74

E-mail: suschek@ifz.tugraz.at

\begin{abstract}
In Austria, the highest potential for sustainable refurbishment is within the sector of single-family houses, which were built between 1945 and 1980. According to estimates, two-thirds of all the possible investments can be assigned to this category. However, there are only a few ambitious models on the supply side, which combine the efficient information and mobilisation of users with a comprehensive technical and ecological offer.

Two of these rare examples will be discussed in this paper. Both models have been operating at a local level for the promotion of sustainable refurbishment for several years. The studied examples are characterised by network structures that are constituted by heterogeneous local social players who aim at quality assurance to enable attractive offers for homeowners. Centrally coordinated units manage both network models. In addition to the management of networks, these units try to fulfil several other functions: public relations, training seminars, strategic development, advisory services for end users and the implementation of refurbishment measures.

Based on a comprehensive analysis and documentation of both models, we will present a critical evaluation of the network activities. It becomes clear that both examples face two major challenges: internally, to cover and productively manage a wide range of different functions in order to stimulate necessary innovations and externally, to influence the sociopolitical framework conditions to increase the demand for noticeable sustainable refurbishment.
\end{abstract}

Keywords: sustainable refurbishment; innovation networks; management of networks; evaluation. 
Reference to this paper should be made as follows: Ornetzeder, M. and Suschek-Berger, J. (2008) 'Innovation networks in the refurbishment sector of Austria: promising approaches waiting for market success', Int. J. Innovation and Sustainable Development, Vol. 3, Nos. 3/4, pp.285-300.

Biographical notes: Dr Michael Ornetzeder is a Senior Researcher at the Institute of Technology Assessment at the Austrian Academy of Sciences. $\mathrm{He}$ is a Lecturer at the University of Agriculture in Vienna and the University of Klagenfurt. He received his PhD from the University of Vienna in 1998. His doctoral thesis was on the social shaping of technology based on a case study on solar technology. In 2004, he was a Senior Researcher at the International Institute for Applied Systems Analysis (IIASA) in Laxenburg, Austria. His current main research interest is within technology studies, with a particular focus on the interrelations of social and technical innovations, shaping and diffusion processes, participation models, user involvement and sustainability. $\mathrm{He}$ is currently working on a national research project that applies lead user and constructive technology assessment approaches to sustainable innovation processes.

Jürgen Suschek-Berger is the Deputy Director of the Interuniversity Research Centre for Technology, Work and Culture (IFZ Department Manager of Energy and Climate) in Graz, Austria. He is a Lecturer at the Universities of Klagenfurt and Graz. He finished his studies in 1993. He is working as a Social Researcher in the fields of environmentally sound procurement and energy and climate. His current main research interests are technology research, strategies of diffusion for renewable energy sources, the management of ecological and social innovations, empirical research and user participation. For his work, he uses quantitative and qualitative methods of empirical research like surveys, interviews or focus groups. He is currently working on projects dealing with the socioeconomic aspects of sustainable buildings, sustainable product development and social networks.

\section{Introduction}

Habitation is, without a doubt, one of the key areas for sustainable development. The construction of residential buildings and necessary infrastructure requires land, energy and an enormous amount of building material. In modern societies, more than one-third of the overall energy consumption is used to serve heating and warm water needs. Along with traffic and industry, habitation is responsible for a considerable share of $\mathrm{CO}_{2}$ emissions.

Concerning the construction of new houses, major advances towards sustainability have been achieved in the last 20 years. In Austria, most new houses feature low energy standards. Moreover, we can see a trend of reducing land use by developing high-density areas (Rohracher and Ornetzeder, 2002). However, the highest ecological potential for improvement is found in the existing building stock.

According to a study on the refurbishment measures for residential buildings in Austria (Schuster et al., 2000), the largest reduction of energy needs could be achieved in private homes that were constructed in the period between 1945 and 1980. Approximately 700000 private houses should be considered for ecological improvements. 
In private households, refurbishment is still dominated by single-step procedures, a strategy oriented toward household finances, insufficient subsidy schemes and the urgency to carry out repairs promptly. In rural areas, the tradition is to do repairs in one's own house or in cooperation with semiprofessional craftsmen. These are conditions that considerably hinder the realisation of comprehensive and ecologically effective refurbishment concepts.

Problems can also be found on the supply side. Most construction companies lack the specific know-how to offer ecologically up-to-date refurbishment solutions. Therefore, locally based company networks that cooperate with different resources and skills are often seen as a solution to this problem.

Two examples of these rare networks have been analysed in a project within the framework of the Austrian research programme 'Building of Tomorrow' (Ornetzeder and Suschek-Berger, 2005). Both the selected cases focus on sustainable refurbishment in the private sector and have been active for several years in two different Austrian regions: the 'Öko-Modell im Alt- und Neubau' (Ecomodel) in the province of Tyrol and the network 'Traumhaus Althaus' (Old dream house) in the province of Vorarlberg. The results of our empirical research are based on 20 qualitative interviews with experts inside and outside the networks, a written survey on network customers and an extensive document analysis. The aim of this study was to understand how these initiatives work, discuss the options for improvement and establish similar initiatives in other regions.

In this paper, which is based on the results of the aforementioned project, we will give a short description of the studied networks, then compare both cases and discuss some of the key functions on a more general level. Then, the focus will be on the possibilities and limitations of networks to shape and stimulate innovation. Before going into the empirical details, we will refer briefly to the theoretical discussion on innovation networks.

\section{Innovation networks and sustainability}

The emergence of new forms of cooperation, located between the principles of 'market' and 'hierarchy', has not only been widely discussed in politics and the public in the last 10 to 15 years but, driven by empirical evidence, has gained importance in the social sciences as well and a number of theoretical concepts have been developed in order to describe and understand these new phenomena. Most concepts refer to social networks and clusters. Clusters are often studied from an economic perspective. The most important theoretical argument is that clusters have the potential to affect competition by increasing the productivity of the companies in the cluster, driving innovation and stimulating the new businesses in the field (Porter, 1980).

Social networks are also discussed in the context of sustainable development as a promising solution. Networks are seen as qualified institutions or new forms of governance to promote the normative objectives of sustainability. From this point of view, networks mobilise the potential for self-organisation, bring together social players who are otherwise separated by traditional institutions or help create a 'milieux innovateur'. Majer (2005) argued that sustainable development is not only a guiding vision, but is closely connected to the implementation of new governance structures such 
as social networks. In a similar way, Minsch (n.d.) stressed the importance of new forms of cooperation for sustainability, which could not succeed without a broad mobilisation of creative problem-solving potentials.

But what is a social network? How can we define this concept? Generally speaking, social networks are loosely coupled individual or organisational systems of action. They are characterised by a common purpose, the logic of communication and negotiation and minimal internal institutional structures. Network members cooperate on a voluntary basis because the positive effects are considered to be higher than the costs that are involved (Fürst, 2001).

Social capital (Coleman, 1988; Putnam, 1993) is considered to be one of the basic principles for interaction in networks. Social capital results from communication, discussions on professional knowledge and values and the willingness to cooperate. It relies on trust, which serves as a basis for the development of cooperation and mutual support.

Social networks operate with paradigmatic forms of governance much more than traditional institutions, which means that they try to influence social action by forming opinions. Paradigmatic governance can be used in networks because it is assumed that the recipients trust the sender. Recipients, as partners in networks, are open to advice (Fürst, 2001).

In our context, company networks with a common focus on innovation are of particular importance. Küppers and Pyka (2002) defined such innovation networks as the interaction processes between a set of heterogeneous players producing innovation at different geographical levels. Innovation networks are cooperative relationships aiming at the invention, development and successful implementation of products and processes. In our case studies, local networks in the building industry try to develop comprehensive offers for homeowners. The innovation is not a single product, but rather a combination of ecological advisory services, planning and the application of various new refurbishment technologies.

Why should companies join innovation networks? The most common argument refers to advantages in competition. Innovation networks are seen as a strategy for success, even under problematic conditions. Küppers (2002) argued that innovations are becoming increasingly more complex and, at the same time, a product has to fulfil the potential user's specific requirements. Innovations must not only function technologically and be economically viable, but also fit into the sociopolitical environment. Therefore, single companies alone are not able to summon up enough intellectual, social and material resources to be successful. Innovation networks could work as a medium through which material and symbolic resources are mobilised and combined (Perry, 1993). Through network interaction, the permanent processes of changing, searching and learning could be stimulated, helping improve the market position of the network partners (Hellmer et al., 1999). Moreover, innovation networks could reduce different kinds of uncertainties in the innovation process if the network partners' various competencies are successfully integrated (Küppers, 2002). In summary, it can be stated that from a theoretical perspective, social networks are considered powerful sources of innovation - at least, under specific conditions.

As empirical case studies show, in practical experience, ideal-type outcomes are seldom achieved. In a comprehensive German study, the authors concluded that the effects of innovation networks are marginal in comparison to the potentials of markets and hierarchy. This is particularly true for Small- and Medium-sized Enterprises (SMEs), 
a sector that is still characterised by distinctive competitiveness, which considerably hinders new forms of cooperation (Hellmer et al., 1999). The importance of regulatory and policy frameworks for the success of technical innovations - even when they have been produced in innovation networks - is demonstrated in a case study on combined heat and power technology in Europe (Weber, 2002). It seems that under real conditions, innovation networks are confronted with a number of internal and external challenges. In this paper, we will concentrate on those aspects that networks are able to control by themselves.

\section{Case studies}

The comprehensive ecologically effective refurbishment of the building stock is one of the key strategies to distinctly reduce $\mathrm{CO}_{2}$ emissions. While in the last years, this potential has been developed quite successfully for multifloor buildings in Austria - refurbishment projects are planned and organised by large housing companies - the situation in the private home sector is still problematic.

In order to stimulate innovation on the supply side, two network activities were started in the provinces of Vorarlberg and Tyrol. Although very close geographically, they have been developed completely independent of each other. Both networks aim to improve offers for private customers. Improvement means that homeowners who are planning to modernise their houses should be able to get up-to-date information on ecological refurbishment. The core idea of these consultations is to promote comprehensive refurbishment concepts, which are able to save energy and maximise the ecological effect. The implementation of single measures that show only little ecological effects and often result in additional repairs within a few years should be avoided. Both initiatives focus on private homeowners, which represent the largest market for building companies in these regions. Moreover, in both cases, the cooperation in local networks should improve the technical know-how and practical skills of the involved companies and promote joint refurbishment projects.

\subsection{Case study 1: Öko-Modell im Alt- und Neubau (Ecomodel) 3.1.1 Background}

The Tyrol-based network 'Eco Model for Old and New Buildings' (Ecomodel) started in 1997. The founder of the network was a grammar school professor with many years of experience with school projects that focused on energy issues. In those projects, pupils had the opportunity to act as energy advisers. They collected relevant data in their own household and, based on that information, they prepared tailor-made advice for energy-saving measures. Some tools and energy guidelines that were developed in the school context were used later in the Ecomodel network.

The main idea of the Ecomodel was to transfer the positive experiences of the school projects to a more professional basis in order to take effect. This became possible in a small rural Tyrolean region - the district of Reutte - because the concept appealed to some municipalities of this district. For those municipalities, the Ecomodel was part of a strategy to block plans for a hydropower station in this ecologically sensitive region. Instead of producing more electricity - which was the idea - the experts of the network 
should effectively detect potential energy savings in households and offer advice on how to deploy it. Eventually, the hydropower station was never realised, mainly due to the activities by local politicians and citizens' initiatives. Today, this part of Reutte is a nature protection area.

The Ecomodel started with a pool of around 20 local companies and institutions, most of them representatives of the construction sector and, therefore, interested in contracts with private homeowners, but a banking institution and a few municipalities were also involved. The aim was to cover the whole range of professionals necessary to accomplish comprehensive refurbishment projects. In the beginning, it was of decisive importance that the initiator was able to convince the potential members in person to become part of the network. Then, it was important that the setup and coordination of network activities were funded by European subsidies for the first three years. In the beginning, the activities were concentrated on retrofits and the dissemination of sustainable energy technology such as solar collectors or biomass heating systems.

In the year 2000, the Ecomodel spread to two other Tyrolean districts. As the EU funding phased out, a new institutional body was established in 2001. The private association, 'Network for Nature, Environment and Economy', took over the networking activities and initiated a comprehensive training course on green buildings, energy efficiency and renewable energy technology. In this context, the activities of the Ecomodel expanded to the planning and construction of new buildings. Around 20 people - the present energy advisers of the network and employees of network members, as well as interested individuals - attended this vocational training. As a result, the training helped improve the quality of the consulting activities. From the point of view of the newly established association, the organisation of the training was also important as a strategy to acquire public funding.

Along with the growth of network activities, conflicts with similar energy consultation centres arose. Consequently, one of the three network centres had to be closed shortly after its launch due to keen competition by the official energy consultants of the Tyrolean government.

Between 2001 and 2004, the activities of the Ecomodel shifted more and more toward consultation on new building development. It was not until the regional subsidy scheme for retrofits was improved that the demand for consulting grew again. In the last years, approximately one-third of the network activities have been connected to refurbishment projects. At present, the network consists of around 30 companies in two Tyrolean districts. Six company-independent experts offer a comprehensive range of consultation services. The activities are organised by two regional offices.

\subsubsection{Main aims and services}

The main aim of the Ecomodel is to promote environmentally sound practices in the construction sector. As in the beginning, when the focus was on energy issues and the refurbishment of private houses, today the activities cover all aspects of sustainable construction, as well as the development of new buildings.

The offered recommendations are designed for private homeowners who are either building a new house or retrofitting an existing building. Specially trained experts who work for the network on a freelance basis give the recommendations. Although most of these activities are financed by the members of the network, the given advice regarding technologies as well as companies is strictly neutral. As we know from our customer 
survey, the quality of this service of the Ecomodel has an excellent reputation. On the one hand, the given advice aims at ecologically comprehensive concepts that cover a wide range of aspects, not only energy issues. On the other hand, the customer with his or her needs and abilities is placed at the centre of the practiced philosophy and the offered advice is seen as a common learning process. The solutions are to be developed step by step. Although the experts try to promote 'green' solutions, all decisions are made together with the customer.

The advice is structured modularly. The first module is about the basic principles of sustainable construction and addresses the specific needs of the customers. This unit is given free of charge (financed by network members). The second module covers the development of a tailor-made energy concept. The third part is even more concrete and provides contract specifications. Furthermore, it is possible to task the experts of the Ecomodel with the execution of construction works and a quality inspection at the end. The most important technical know-how is summarised in a written booklet, which is available for free from local municipalities.

\subsubsection{Network structure and mode of operation}

Today, the Ecomodel network involves about 30 members. Most of them represent the local construction industry, but there are also two banking institutions and a few municipalities. The private association 'Network for Nature, Environment and Economy' serves as legal body of the Ecomodel. The membership and cooperation within the network is fixed by a written agreement to be confirmed yearly. To a great extent, the network is self-organised. Once a year, all of the relevant partners get together at the annual general meeting to discuss and decide the principal direction of the Ecomodel.

As provided in the agreement, the members of the Ecomodel commit to fostering the idea of sustainable construction, supporting the vocational trainings of employees and network experts, cooperating with the other members of the network in concrete projects and being a part of the networks' publicity campaigns. The membership fee is 1100 euros per year, without regard to the size of the company.

The members of the network are able to profit in several ways: through joint marketing activities, training opportunities for employees or getting in touch with potential customers at 'mini-fairs' organised by the Ecomodel centres. Moreover, the members of the network have direct access to the data of the people who make use of the Ecomodel's consultation services (advisers have to inform the customers at the beginning of every consultation and only when they agree is personal information used in this way). For most network members, acquiring access to new customers was the main motivation to join. The companies that had left the network after some years of experience mentioned the same reason - their expectations regarding new customers were not fulfilled. It seems to be obvious that outstanding consultation services do not directly result in corresponding contracts and project realisation.

\subsection{Case study 2: Traumhaus Althaus (Old dream house)}

\subsubsection{Background}

The network 'Traumhaus Althaus' was established in the year 2000 by the Energieinstitut Vorarlberg (Energy Institute of Vorarlberg) in the province of Vorarlberg. The Energy Institute is well known as the principal consulting and research institute 
in this province. Around 15 experts in the areas of building, industry and municipality conduct research and consultations. Most of the activities of this think tank are sponsored by public authorities.

The central motivation for the Old dream house initiative was to improve the know-how and practical skills in the construction industry regarding comprehensive refurbishment projects. While in the 1990s, the main focus was on the development of new buildings (and, as a consequence, the standards regarding energy efficiency and green materials improved tremendously), the situation regarding refurbishments lagged clearly behind. For the experts at the Energy Institute, it soon became clear that the existing building stock would represent a huge potential for ecological improvements. As the local government started to change the support programmes at the end of the 1990 s - shifting money from new developments to refurbishments - it became even more important to start a kind of qualification network for these specific tasks.

In the preparation phase, the Energy Institute conducted a survey in order to learn more about the needs and interests of homeowners. Together with an advertising agency, they prepared a public relations concept that includes the brand 'Old dream house', based on the idea that even an old building could be 'ideal as a dream' if it is modernised according to high (ecological) standards. As a next step, they launched a marketing campaign in order to inform the general public about the advantages of ecological refurbishments and the changed subsidy programmes. At the same time, the project team at the Energy Institute started to recruit members for the company network using personal contacts at local fairs, as well as a direct mail, covering more than 2000 addresses. Around 300 participants came to the kickoff meeting.

The Old dream house network started in January 2000 mainly as a platform for vocational training, with almost 150 institutional members. Quite similar to the concept of the Tyrolean Ecomodel, the idea here was also to cover a whole range of necessary professions. The long list of founder members included architects, builders, roofers, installers, electricians, solar energy experts and many more.

Within the first two years, the network management organised eight network days with around 40 presentations and more than 70 different workshops. Those activities were not only aimed at improving the knowledge of the company representatives; the network management also intended to provide as much space as possible for personal interaction in order to establish mutual trust. This was seen as a major precondition for doing joint contracts in the future.

Because of the huge number of members, it soon became clear that the organisation of those platform days would be a serious challenge for the Energy Institute. It also turned out that it would not be easy to create a programme that covers all the different needs of the participants.

After two years, the network members had to decide for the first time whether to continue their membership or leave the network. Surprisingly, a huge number of members left the network at this point. In most cases, the companies had the feeling that they had learned enough and, therefore, it would not be necessary to continue. In other cases, the companies quit their membership because they were no longer interested in keeping the high quality standards of the network. 
As a result of these experiences, the network management adapted the original concept. Quality regarding training as well as practical implementation at the construction site became even more important. The rules and methods to guarantee internal quality standards were reworked completely. Moreover, the membership fee was notably increased. In 2003, the network continued with around 60 companies.

\subsubsection{Main aims and services}

The main focus of network management is on know-how transfer and quality control. The network members should be able to carry out comprehensive refurbishment projects that meet high ecological standards. Therefore, refurbishment projects have to consider the following principles:

- maintain usable inventory

- reduce energy losses

- use raw materials sparingly and prefer renewable materials

- $\quad$ use recycled and recyclable materials

- heat with renewable forms of energy like biomass or solar

- consider the long service life of buildings (Energieinstitut Vorarlberg, 2003).

In order to meet those principles, refurbishment projects in most cases have to be as comprehensive as possible - it is not enough to renew the windows or the old heating system. For these purposes, two aspects seem to be of core importance. Firstly, specialists have to learn to think in a broader way (seeing the whole picture) and secondly, they need more competencies in cooperating with other specialists (coordinating the work at interfaces).

These two aspects are taken up repeatedly in the vocational training programme. As already mentioned, the programme is organised in the form of network days. Beside a broad range of technical seminars, company management issues are also covered. The quality of this offer is rated very high by members, even among those who left the network after the first two years.

Besides the training programme, the network organises consumer-oriented marketing activities. Private homeowners are regularly informed about the advantages of ecological refurbishments, the quality standards of the network and the available public subsidies for refurbishment projects. On these occasions, the management strives to establish the brand 'Old dream house' as a widely known and accepted high-quality label.

\subsubsection{Network structure and mode of operation}

In this case, the network management takes up a central position in form as well as in content. It has defined the rules and developed the guidelines. The management organises the training seminars and monitors the quality of the output. Most of the communication, even between single members, flows through the central management. The members are rather seen as customers than as active shapers of the network. Contrary to the first case study, the members of the Old dream house network are not in a position to influence the strategic orientation of the network. 
The network members have to pay a yearly fee (between 900 and 2100 euros) depending on the number of employees. They also have to abide by a special codex regarding technical and procedural rules. The codex covers the instructions for the customer relationship, a commitment to the concept of sustainability (with regard to construction/refurbishment) and some rules for cooperation within the network.

The most important element is vocational training. At least one employee of each network company has to be qualified as an energy and ecological building expert. These experts have to participate in additional training programmes and should spread know-how and skills within their own company. The management annually monitors the effectiveness of the training using questionnaires.

In Table 1, we try to compare both case studies. It turns out that there are some striking similarities (on a more general level), as well as some interesting differences (e.g., regarding mode of operation, some core competencies or the membership structure). We will refer to this overview in the discussion section.

Table 1 The common and different network features

\begin{tabular}{|c|c|c|}
\hline Common features & \multicolumn{2}{|l|}{ Short description } \\
\hline General goals & \multicolumn{2}{|c|}{ Implementation of comprehensive ecological retrofit innovations } \\
\hline & \multicolumn{2}{|c|}{ Focus on private homes } \\
\hline & \multicolumn{2}{|c|}{ Innovations through cooperation in local networks } \\
\hline Training focus & \multicolumn{2}{|c|}{ Technological and practical skills for energy-saving retrofit measures } \\
\hline Organisation & \multicolumn{2}{|c|}{ Strategic networks with limited membership (to be renewed annually) } \\
\hline & \multicolumn{2}{|c|}{$\begin{array}{l}\text { Cooperation with autonomous companies, with partly } \\
\text { overlapping interests }\end{array}$} \\
\hline & \multicolumn{2}{|l|}{ Strong management } \\
\hline Differences & Ecomodel & Old dream house \\
\hline Starting point & $\begin{array}{l}\text { Energy advice for private } \\
\text { households }\end{array}$ & $\begin{array}{l}\text { Know-how transfer to the } \\
\text { building industry }\end{array}$ \\
\hline Contact with customers & $\begin{array}{l}\text { Direct contact through } \\
\text { energy consultancy }\end{array}$ & Public relations \\
\hline $\begin{array}{l}\text { Core competence of the } \\
\text { network management }\end{array}$ & $\begin{array}{l}\text { Networking and energy } \\
\text { consultancy }\end{array}$ & $\begin{array}{l}\text { Research, energy consultancy, } \\
\text { education and training }\end{array}$ \\
\hline Size & About 30 network partners & $\begin{array}{l}\text { About } 60 \text { partners } \\
\text { (originally 160) }\end{array}$ \\
\hline Membership structure & Heterogeneous & Branch-specific \\
\hline Commitments & Informal & More formal (contract and codex) \\
\hline Financing & $\begin{array}{l}\text { Membership fees, earnings from } \\
\text { comprehensive consultancies, } \\
\text { project money }\end{array}$ & $\begin{array}{l}\text { Subsidies from the local } \\
\text { government, membership fees }\end{array}$ \\
\hline
\end{tabular}

\section{Analysis of the central functions}

In order to meet the self-assigned goals, the studied innovation networks must serve various functions. The network management has to coordinate strategic development and is responsible for the internal flow of information. Moreover, the management 
organises internal training seminars and supports communication with the customers (through consulting and/or public relations). All of these activities aim to develop and implement ecologically effective retrofit projects. In the following paragraphs, we will describe and analyse these main network functions in detail.

\subsection{Strategic development}

Dealing with strategic questions is of decisive importance for the development of innovation networks. In these cases, questions could refer to technical aspects ('How do we define ecological refurbishment?'), as well as the coordination of different tasks ('How could we combine information campaigns, consultation services, training seminars, etc., with an effective strategy?'). Strategic decisions should also guarantee good financial management and public relations resources.

In both cases, the management is mainly responsible for strategic network development. In the case of the Old dream house network, strategic decisions are discussed in a steering group that consists of company representatives and chaired by the responsible management project leader. For basic decisions, the main sponsor of the network activities, the government of Vorarlberg, must be consulted. In the Tyrolean case, the association 'Network for Nature, Environment and Economy' is concerned firstly with the development of strategies. However, the network's energy and building consultants - a core group of about five persons - are closely involved in all strategic discussions as well. After consulting this core group, the annual working programme is presented and discussed at a meeting with the network companies. In contrast to the situation in Vorarlberg, the strategic development of the Ecomodel network is not institutionally linked to the local government's housing department.

\subsection{Network management}

Network management includes the administration as well as support of network members, the exchange of information and the handling of financial and contractual concerns.

In the network 'Traumhaus Althaus', the management tasks are operated by the responsible project group at the Energy Institute of Vorarlberg. The activities are financed by governmental funds, as well as membership fees. In Tyrol, the network is divided into two independent regional networks, which are managed by separate offices. Due to a much smaller number of members in the Ecomodel, the office representatives are able to contact each member personally at least once a year. Although the management in both cases is very active, both networks are confronted with decreasing numbers of members.

\subsection{Internal qualification and training}

The network partners' internal qualification refers firstly to theoretical as well as practical know-how, which is necessary for implementing up-to-date ecological retrofits. In both cases, qualification training is organised by the management.

This aspect is of major importance in the Old dream house network. The network management has easy access to the professional and personal resources of the Energy Institute, which is complemented by external experts, if necessary. Qualification training 
is offered four days per year. Each network partner should attend at least two training days. In interviews, the participants unanimously report on the high quality of these training programmes. For many companies, the access to this kind of knowledge was one of their reasons for joining the network.

In the second case, internal qualification does not play such a major role. In fact, there is a training programme for companies, but it takes place only once a year.

In spite of the differences in the two cases, it appears difficult to offer attractive training programmes for a longer period of time due to the problems involved in designing 'one-size-fits-all' seminars in heterogeneous networks.

\subsection{Public relations}

Both network managements run public relations activities. These activities include information for the general public about the network activities, as well as the attempts to set up trademarks for the networks. In the case of the Ecomodel, which is more customer-oriented, the information aspect is of major importance. The network management tries to inform the homeowners by means of advertisements in local newspapers and other promotional material. Homeowners should recognise and make use of the range of network services. Establishing a brand or promoting network partners is of less importance in Tyrol.

With the Old dream house network, the main focus is on brand development. In the first two years, the management had launched several advertising campaigns throughout the province. The trademark 'Old dream house' was supposed to become well known in Vorarlberg. As the results of the customer survey show, this strategy did in fact lead to a larger amount of public awareness - compared to the Ecomodel in Tyrol - but the goal to establish 'Old dream house' as a quality label has not yet been accomplished. It is also obvious that only a small number of network members use the Old dream house promotional material; their own original corporate logo is of much greater relevance. As a consequence, the capability of the network's public relations activities to acquire new customers is very limited.

\subsection{Advice on energy use and green technology}

Consultancy for private homeowners is an integrated part of the network activities only in the Ecomodel network. Free initial consultations are financed by membership fees paid by all participating companies. In Vorarlberg, consultations are given by a group of experts sponsored by the local government. The Old dream house management is in contact with this consultancy group, but there is no direct link to the network activities.

In both provinces, the advising services have a very good reputation in public opinion. The given information is valuable in content and classified as neutral with respect to companies and products.

\subsection{Implementing refurbishment projects}

Both networks are only indirectly involved in refurbishment projects. Contractors are network companies or project-based network partner cooperations. 
Although many homeowners use advising services, the dissemination of comprehensive ecological retrofits is still extremely limited. Therefore, the cooperations between network members are more an exception than a rule. One of the central goals of the network activities - to push ahead with innovation in refurbishment projects - has not yet been achieved.

A long tradition in the construction sector is to form project-based cooperations with complementary trades. These cooperations are often based purely on mutual trust and stabilised by ongoing cooperations. Unfortunately, the studied networks have not stimulated project-based cooperations such as these so far.

The practical impact of the network activities on innovation is qualitative rather than quantitative, i.e., the networks' improved offers have not stimulated as many projects as expected, but the technical quality and the scope of single projects have improved considerably.

Table 2 gives an overview of the central functions of the studied networks and characterises these functions by main tasks.

Table 2 The central functions and related tasks in refurbishment networks

\begin{tabular}{ll}
\hline Functions & Tasks \\
\hline Strategic development & Formulation of technological guidelines on refurbishment quality standards \\
& Coordination of different substrategies (information campaigns, advice \\
& services, training seminars, etc.) \\
& Network setup and development \\
& Guarantee of financial resources (subsidies, fees, fund raising) \\
Network management & Administration of contracts \\
& Support and attendance of network members \\
& Supply and allocation of information \\
Qualification & Development of training seminars for network partners \\
and training & Quality assurance \\
Public relations & Training seminars for advisers (Ecomodel only) \\
& Ecological refurbishment fairs \\
& Production of promotional material \\
& Information campaigns, advertisements in local newspapers \\
& Trademark promotion \\
General advice (focus refurbishment) & Customised advisory service \\
(Ecomodel only) & Energy and refurbishment concepts \\
Implementation of & Monitoring \\
refurbishment projects & Tendering and planning \\
& Site inspection \\
\hline
\end{tabular}




\section{Discussion}

The studied refurbishment initiatives are heterogeneous innovation networks that are thematically as well as organisationally controlled by central management units. Although important decisions are made in coordination with most network partners, self-organised communication between the company partners is rare. Social capital as a principle for interaction is clearly underdeveloped and, therefore, not relevant so far. In the building industry, social capital is based mainly on positive joint-project experiences. Company representatives' 'get-togethers' in training seminars have a positive effect, but happen much too seldom to establish stable and trusting connections. There appears to be a correlation between the size of the network and the opportunity to set up social capital. With the increase in size, it is more difficult to establish trusting relations. Another problem with size is the membership structure. It is obvious that networks consisting partially of direct competitors are at a disadvantage regarding trust and cooperation.

As we can see in our examples, the networks have to cover a wide range of functions that are often very different from one another. This variety could also act as an indicator for the complexity of innovations in the field of sustainable refurbishment. This is not about the development of a new product and its successful market launch, but rather, the networks have to create several sets of services and products based on new knowledge, skills and technology, which can take specific shapes at the project level.

A feature of both networks is that the innovation focus has been fixed from the outset on sustainable refurbishment. Perhaps this precondition may explain the dominant role of the management units. It is likely that self-organised company networks are more open and market-oriented and it seems that the core competence of the management shows far-reaching effects on the nature of the networks. In both cases, the technical know-how on energy issues and sustainable refurbishment of the initiators was of major importance.

The transfer of knowledge and skills is clearly the main characteristic of both networks. In the Ecomodel, the homeowners are provided with comprehensive, up-to-date refurbishment information. The Old dream house network is very good at qualifying and training. However, the combination of internal qualification and networking demonstrates some problems as well. The size of the network is in structural conflict with the thematic alignment. The more different interests are to be considered, the wider and, therefore, more time-consuming and expensive the programme development is. It also appears to be very difficult to offer a relevant and interesting qualification programme over a longer period.

Setting up innovation networks does not necessarily lead to market-relevant innovations - of course, this is not only true for our cases. In terms of market success, the impact of the studied networks is still minor. Although the situation on the supply side has improved considerably, the possibilities of networks to influence demand is obviously limited. For example, the necessary resources to launch and sustain a new trademark and inform the public continually about the network activities are far beyond the network's means. In both examples, the management tries to close the gap between the market (customers) and hierarchy (politics); the impact especially on the regulatory framework (e.g., building code, subsidy scheme) - which is crucial for the market success of comprehensive retrofit concepts - is not strong enough. The underdeveloped 
market is the main reason for the small number of newly created cooperations on the project level. However, the cooperations of complementary trades on a very local level would be necessary to cope with comprehensive retrofit jobs in the future.

\section{Summary and conclusions}

In this paper, we have presented two case studies on innovation networks in the field of sustainable refurbishment. From an ecological perspective, the modernisation of private houses offers a large potential to reduce $\mathrm{CO}_{2}$ emissions through energy savings. Innovation networks should, therefore, close the existing gap between demand and supply by improving the technical offer, as well as by stimulating the demand.

From a theoretical view, innovation networks are seen as a strategy to cope with these challenges. In innovation networks, material and symbolic resources can be mobilised and combined. Through interaction within networks, the processes of changing, searching and learning can be stimulated, reducing uncertainties in the innovation process and helping improve the market position of the network partners. If specific conditions are fulfilled, social networks are considered powerful sources of innovation. However, empirical studies show that under real conditions, innovation networks are confronted with a number of internal and external problems.

Both of the presented innovation networks focus on sustainable refurbishment in the private sector and both have been active in two different Austrian regions, trying to promote and support innovations for sustainable refurbishment on the local level for several years. Although very close in geographical terms, both initiatives were developed independently of one another. In spite of this, we found many similarities. In both cases, the network activities are coordinated by central units. In addition to network management tasks, these units are also responsible for several other functions: public relations, training seminars, strategic development, advisory services for end users and the implementation of refurbishment measures. The necessity to cover such a wide range of different functions is an indication of the complexity of innovations in the field of sustainable refurbishment.

Both networks are driven by the idea of changing practices in the building industry towards sustainability. This goal was fixed from the outset and is closely linked to the initiator's core competence. It seems that these core competencies show strong effects on the development of the networks. Therefore, it is not surprising that the transfer of knowledge and skills is one of the strengths in both cases.

Learning about sustainable technology and practical skills together does not lead to the development of sufficient social capital. Moreover, it seems problematic if direct competitors participate in one and the same network. In order to establish trustful relations, the project-based experiences of mutual cooperations are of vital importance.

As our case studies show, setting up innovation networks does not necessarily lead to market relevant innovations. There are limitations on both sides. On the one hand, the influence on the performance and strategies of the members - concerning skills, knowledge and offered products - is limited. On the other hand, these networks are not able to open up the market for sustainable refurbishment. The resources for public relations are not sufficient. In order to increase the demand for sustainable refurbishment, changes are needed, above all, in the regulatory framework. 


\section{Acknowledgements}

We are grateful to the Ministry for Transport, Innovation and Technology (BMVIT) for funding our research and to the Austrian Society for Environment and Technology (OGUT) for managing the programme 'Building of Tomorrow'.

\section{References}

Coleman, J. (1988) 'Social capital in the creation of human capital', American Journal of Sociology, Vol. 94, Supplement, pp.95-120.

Energieinstitut Vorarlberg (Ed.) (2003) Neuer Energien für alte Häuser. Ein Leitfaden zur energieffizienten und ökologischen Wohnbausanierung, Dornbirn.

Fürst, D. (2001) 'Die Bedeutung von Netzwerken in modernen Gesellschaften', in H. Kanning (Ed.) (2001) Netzwerke und Nachhaltigkeit: Vernetzte Probleme - vernetztes Denken vernetzte Lösungen, Schriftenreihe des Doktoranden-Netzwerkes Nachhaltiges Wirtschaften e.V., Band 6, Hannover, pp.5-15.

Hellmer, F., Friese, Chr., Krollos, H. and Krumbein, H. (1999) Mythos Netzwerke - Regionale Innovationsprozesse zwischen Kontinuität und Wandel, Edition sigma, Berlin.

Küppers, G. (2002) 'Complexity, self-organisation and innovation networks: a new theoretical approach', in A. Pyka and G. Küppers (Eds.) Innovation Networks, Theory and Practice, Cheltenham: Edward Elgar, pp.22-52.

Küppers, G. and Pyka, A. (2002) 'The self-organisation of innovation networks: introductory remarks', in A. Pyka and G. Küppers (Eds.) Innovation Networks, Theory and Practice, Cheltenham: Edward Elgar, pp.3-21.

Majer, H. (2005) 'Institutionelle Innovationen für Nachhaltigkeit', http://www.nachhaltigkeit.at/ reportagen.php3?id=9\#K8 (accessed 5 February 2006).

Minsch, J. (n.d.) 'Gedanken zu einer politischen Kultur der Nachhaltigkeit', http://www.iff. ac.at/socec/backdoor/sose05-ring-sozoek/03_Minsch_04.pdf (accessed 15 April 2005).

Ornetzeder, M. and Suschek-Berger, J. (2005) 'Einfamilienhäuser innovativ sanieren: Erfolgskriterien und Übertragbarkeit von Best-Practice-Modellen im Einfamilienhausbereich', Berichte aus der Energie- und Umweltforschung, Ministry for Transport, Innovation and Technology, Vienna, Vol. 43.

Perry, N. (1993) 'Scientific communication, innovation networks and organization structures', Journal of Management Studies, Vol. 30, No. 6, pp.957-974.

Porter, M. (1980) Competitive Strategy, New York: Free Press.

Putnam, R. (1993) Making Democracy Work, Princeton: Princeton University Press.

Rohracher, H. and Ornetzeder, M. (2002) 'Contextualising green buildings: improving social learning processes between users and producers', Built Environment, Vol. 28, No. 1, pp.73-84.

Schuster, G., et al. (2000) 'Wärmeschutzmaßnahmen an Wohngebäuden: Grundlagen für CO2-Einsparpotentiale des österreichischen Nachkriegswohnbestandes', Zentrum für Bauen und Umwelt, Krems.

Weber, M. (2002) 'Innovation networks and the transformation of large socio-technical systems: the case of combined heat and power technology', in A. Pyka and G. Küppers (Eds.) Innovation Networks, Theory and Practice, Cheltenham: Edward Elgar, pp.133-168. 